\title{
Palliative Endoscopic Therapy of Esophageal Cancer
}

\author{
Thomas Rabenstein \\ Department of Gastroenterology, Diakonissen Speyer-Mannheim, Diakonissen Krankenhaus Speyer, Speyer, Germany
}

\section{Keywords}

Esophageal cancer - Palliative endoscopic therapy . Laser - Argon-plasma coagulation - APC - Self-expandable metal stents $\cdot$ SEMS

\section{Summary}

Background: This is a review of endoscopic therapy in the setting of palliative management of patients suffering from esophageal cancer (EC). Unfortunately, many cases of EC present in a stage of disease in which curative therapy is not possible. The maintenance of quality of life includes the ability to swallow and of oral feeding, pain control, and the prevention of bleeding. Methods: $A$ review of the current literature was performed. Results: Many endoscopic methods are available for the management of dysphagia, of which dilation, endoluminal tumor destruction, stenting, and brachytherapy are the most common. Conclusion: Surgical palliation should be avoided as much as possible since the alternatives show at least the same efficacy and have fewer complications.

(C) 2015 S. Karger GmbH, Freiburg

\section{Introduction}

Unfortunately, many cases of esophageal cancer (EC) present in a stage of disease in which curative therapy is not possible. This may be the case due to the local stage of disease, lymph node and distant organ metastasis, technically irresectable tumors, poor surgical candidates, or patients who decline surgery. Finally, this heterogeneous group includes patients with potentially resectable tumors who do not improve during neoadjuvant therapy and who have to switch to palliative modalities [1].

The options of palliative therapy in those situations are mostly a far cry from what patients would like to hear during the discussion of possibilities; a prolonged progression-free survival is possible only in the minority of cases. The goal of palliation is control of the tumor and of tumor-induced symptoms rather than cure. The maintenance of quality of life includes the ability to swallow and of oral feeding, pain control, and the prevention of bleeding.

Palliative radiation with or without chemotherapy, which are the most effective long-term modalities for tumor control, is discussed by Fokas and Rödel [2] in this special issue. Since the effects of radiation do not show immediately, endoscopic interventions may help to bridge this period. In the following, only those modalities will be summarized which help by either single or repeated minimally invasive interventions with a low complication risk but which still offer more benefits than best supportive care alone.

\section{Dysphagia}

Any difficulty to swallow food, liquids, or oral secretions is summarized by the term dysphagia [3]. Dysphagia may be induced by former therapy, i.e. radiation therapy, surgery, endoscopic resection, or local ablation therapy, by the EC itself, or by additional complications such as food impaction, Candida overgrowth, or stent dislocation. Thus, diagnostic esophagogastroduodenoscopy with or without radiological controlled contrast swallowing is the primary diagnostic approach to identify the origin of symptoms and to rule out differential diagnosis [4]. In many cases therapeutic interventions can start during the same procedure; thus, informed consent should include the major endoscopic modalities from the beginning in order to shorten the hospital stay. Dysphagia grading systems, such as the grading scale of the Radiation Therapy Oncology Group (RTOG) or the European Organization of Research and Treatment of Cancer (EORTC), focus on radiation-induced benign strictures and are mostly not helpful in the setting of palliative care. Table 1 gives an overview of endoscopic modalities for the treatment of dysphagia [4]. Accordingly, a systematic review was performed by Sreedharan et al. [5]. In a 2013 guideline, the American

\section{KARGER \\ Fax +497614520714 Information@Karger.com} www.karger.com

\section{() 2015 S. Karger GmbH, Freiburg}

$1662-6664 / 15 / 0315-0354 \$ 39.50 / 0$
Prof. Dr. med. Thomas Rabenstein

Innere Medizin, Gastroenterologie und gastroenterologische Onkologie

Diakonissen Speyer-Mannheim, Diakonissen-Stiftungs-Krankenhaus Speyer

Paul-Egell-Straße 33, 67346 Speyer, Germany

thomas.rabenstein@diakonissen.de 
Table 1. Endoscopic modalities for the treatment of dysphagia
Placement of self-expandable metal stents (SEMS)

Dilation/bouginage

Ablation therapy (argon-plasma coagulation, LASER, photodynamic therapy)

Endoscopic resection or injection

Brachytherapy

Percutaneous endoscopic (or sonographic) gastrostomy

Society for Gastrointestinal Endoscopy (ASGE) recommended endoscopic options as the preferred method for palliation of dysphagia and fistulas [6].

\section{Esophageal Dilation}

Esophageal dilation is a good and safe method for immediate improvement of dysphagia [6-8]. Depending on the grade of obstruction and the rigidity of the tumor, it is performed in several sessions up to a final diameter of about $17 \mathrm{~mm}$. Guide-wire assistance and fluoroscopic control are strongly recommended to reduce the risk of perforation during insertion of the bougies. Blind dilation by Maloney bougies during radiotherapy has the highest risk of perforation. The dilation effect may persist over a period of up to 3 months with great variety. The poorest results are achieved in case of cardia involvement und long-segment extraluminal masses. We achieve the best results in slow-growing and well-differentiated adenocarcinoma of the esophagus when 3-monthly dilation therapy is combined with thermal destruction of exophytic parts of the tumor by means of argon-plasma coagulation (APC). In Wiesbaden, a former German center for EC, several patients could be successfully managed for 12-24 months using this setting, a time period in which self-expandable metal stents (SEMS) usually develop long-term complications. Esophageal dilation may be performed by through-the-scope balloons as well [6-8].

\section{Endoluminal Tumor Destruction}

Several methods are available which allow safe and effective endoluminal tumor destruction with the aim of patency of the esophagus for swallowing. All options have a certain risk of complications. While therapy-induced tumor hemorrhage can be successfully managed immediately by endoscopy itself, the treatment of perforations and fistulas is difficult.

\section{Laser Therapy}

Laser therapy is the traditional form of endoscopic thermal tumor destruction. Usually, a neodymium:yttrium-aluminum-garnet (Nd:YAG) laser is used in 3-4 sessions $[9,10]$. In more than $90 \%$ of cases luminal patency may be achieved within the tubular part of the esophagus, but anatomically the cardia and the cricopharyngeus are more difficult to access. Overall, the functional success of laser therapy ranges from 70 to $80 \%$, which is the benchmark for alternative methods of tumor destructions, which are usually cheaper and easier to handle than laser.

\section{Argon-Plasma Coagulation}

APC is a monopolar, non-contact, high-frequency electrocautery technique that uses electrically charged argon gas to cause coagulation and tumor destruction as well as to stop gastrointestinal bleeding due to various reasons [11]. Since the electric energy is sort of sprayed on the tissue by the argon gas flow, the thermally induced tissue necrosis is superficial and usually limited to a depth of 1-2 mm, which increases the safety of the procedure. The probe is applied through the working channel of the endoscope. APC generators are present in most endoscopy units of the world, while the availability of lasers is mostly limited to specialized endoscopic centers. This makes the technique quickly available and easy to use. Several daily sessions are usually necessary for sustained patency of the esophagus. In one study, an overall response to APC was seen in $85 \%$, and dysphagia improved in $94 \%$ of patients [11]. APC can be combined with alternative methods for sustained patency. In a comparative study, the time period to the first dysphagia recurrence was 35 days for APC alone, 88 days for APC + brachytherapy, and 59 days for APC + photodynamic therapy (PDT) [12].

\section{Photodynamic Therapy}

PDT is a tissue ablation technique using a photosensitizing agent (porfimer sodium (Photophrin ${ }^{\circledR}$; Lederle Parenterals, Carolina, Puerto Rico)) that accumulates in the tissue after intravenous injection [13]. The accumulation of the agent within tumor cells is assumed to be higher than in other cells. In combination with laser light exposure of a certain wavelength $(630 \mathrm{~nm})$ through the working channel of the endoscope some time after injection, semiselective photochemical tumor destruction can be achieved. The lightinduced cytotoxic effect arises via the production of singlet oxygen which damages the microvascular structure of the tumor and leads to ischemia [13]. PDT is able to reduce dysphagia as a single treatment modality, but it can also be repeated. Response is also documented in cases of recurrence after definitive radiochemotherapy or in case of tumor overgrowth during stent therapy. Combination with APC is also possible. PDT is easier to apply than classical laser therapy and is better tolerated by patients [13]. Nevertheless, a lowpower laser and special equipment are necessary to activate the drug, and the expenses for the drug also need to be added. A special problem is the general light toxicity for 8 to 12 weeks after treatment which cannot be prevented other than by an avoidance of exposure to daylight. PDT is currently less often used than several years ago due to the widespread availability of stent therapy and APC, both of which seem to be alternatives that can be easier applied.

In a prospective, randomized trial involving 236 patients, PDT and laser therapy had a similar overall efficacy in terms of dysphagia relief. Some advantages of PDT were reported for longer tumors and for tumors of the upper third of the esophagus. PDT showed fewer perforations ( 1 vs. 7) and less adverse events (3 vs. 19\%) compared to Nd:YAG laser but had a photosensitivity of $19 \%$ [14]. 


\section{Brachytherapy}

Brachytherapy offers the possibility of achieving high radiation doses in a localized area while sparing out surrounding structures [15-19]. The therapeutic effect is not immediate but more durable than stenting. Therefore, brachytherapy is an alternative to SEMS, especially when the extension of extraluminal tumors is limited and long-term survival is assumed. However, not all patients are good candidates for brachytherapy: If life expectancy is less than 3 months, SEMS help immediately and are therefore more effective than brachytherapy. In cases of a life expectancy of more than 6 months brachytherapy is also not recommended, and in case of former radiochemotherapy the risk of inducing fistulas is high. Within these limitations brachytherapy may be helpful for patients. In a clinical trial comparing SEMS with brachytherapy as single treatment modalities, SEMS showed a more rapid improvement within 30 days; however, brachytherapy was associated with a significantly reduced dysphagia at later time points and significantly more overall days with almost no dysphagia ( 115 vs. 82). Additionally, brachytherapy had a lower complication rate, better quality of life scores, and a less frequent need of repeated treatment due to recurrent or persistent dysphagia [18].

\section{Injection of Absolute Alcohol}

Injection of absolute alcohol is inexpensive and easy to apply by standard endoscopic equipment. Nevertheless, there is only limited experience regarding this method, and the tracking of the chemical agents is uncontrolled; therefore, complications like chest pain, mediastinitis, fistulas, and perforation are common [20,21]. The therapeutic effect is mostly short-lasting. In summary, this method cannot be recommended [22].

\section{Injection of Cisplatin/Epinephrine Gel}

Only pilot studies are available for this more recent approach to minimally invasive tumor destruction by means of injection of a chemotherapy-containing gel into the tumor. An objective and symptomatic response could be seen but further investigation is mandatory, especially if combined with other techniques [23, 24].

\section{Cryospray Ablation}

Non-contact supercooling for inducing tissue necrosis is another method to palliate EC. In a series of 79 patients with EC, $63 \%$ of patients who completed therapy showed a complete intraluminal response; however, 30 patients were still under treatment at the time of reporting. Most patients in the study were pretreated with other modalities, and only those developed benign strictures (overall 13\%) $[25,26]$.

\section{Endoscopic Mucosal Resection and Endoscopic Submucosal \\ Dissection}

Both endoscopic mucosal resection (EMR, ER) and endoscopic submucosal dissection (ESD) are used for local cure of early-stage superficial EC (T1a) [27-31]. Some patients with submucosal tumor stage or additional risk factors for undetected lymph node involvement documented after EMR and ESD who are unfit for curative surgical resection or refuse operation may also have a long-term benefit from complete local resection. This is due to the fact that the risk of lymph node and other metastasis at this stage of the disease (T1b) is about $10-20 \%$ in Barrett's adenocarcinoma, while it is far from $100 \%$ in case of squamous cell cancer of the esophagus [32]. Nevertheless, currently there is no place for EMR or ESD in the field of palliative therapy of advanced tumor stages.

\section{Surgical Palliation}

Palliative surgical resection and palliative surgical bypass are no longer considered as adequate within the field of palliative management of EC [33,34]. Perioperative morbidity and mortality rates are high, and the functional results are not better than what we can achieve with less invasive modalities. Additionally, potentially curative alternatives, such as definitive radiochemotherapy, may be impossible after a palliative surgical attempt.

\section{Expandable Stents in the Esophagus}

Expandable stents are one of the most common modalities for the treatment of malignant obstruction of the esophagus in incurable tumor stages and for the closure of tumor- or radiation-related fistula. They are both safe and easy to apply, using standard equipment which is present in every endoscopy unit. Stents offer a fast improvement of dysphagia. In a 2013 guideline, the ASGE recommended stents as the preferred method for palliation of dysphagia and fistulas [6]. Stent placement is also possible in proximal or cervical EC [1].

In most cases, prior dilation of the tumor stenosis has to be performed for diagnostic purposes as well as for exact measurement of the localization and length of the stenosis, even if placement is also possible without prior dilation [4]. Stent placement is also effective in case of compression of the esophagus by extraesophageal malignancies. However, the degree of symptom improvement may be less than for intraesophageal cancer, and stent migrations are more often seen [3]. SEMS are also useful in case of EC recurrence with or without fistula.

Three types of stents are available: i) SEMS, ii) self-expandable plastic stents, and iii) biodegradable stents, of which SEMS are dominating and will be focused on in this article.

\section{Self-Expandable Metal Stents}

SEMS are available from many manufacturers in different diameters, lengths, and structures of the metal mesh. Many of the stents are composed of nitinol, an alloy of nickel und titanium. We principally distinguish three varieties: uncovered, partly covered, and fully covered stents. Additionally, some stent types are equipped with an anti-reflux valve. An overview on SEMS is given in table 2. While older uncovered stents could not be removed, covered stents are principally removable. They are also used for the short-term treatment of some non-malignant obstructions, fistulas, and postoperative anastomosis insufficiency. 
Table 2. Overview about current self-expandable metal stents (SEMS)

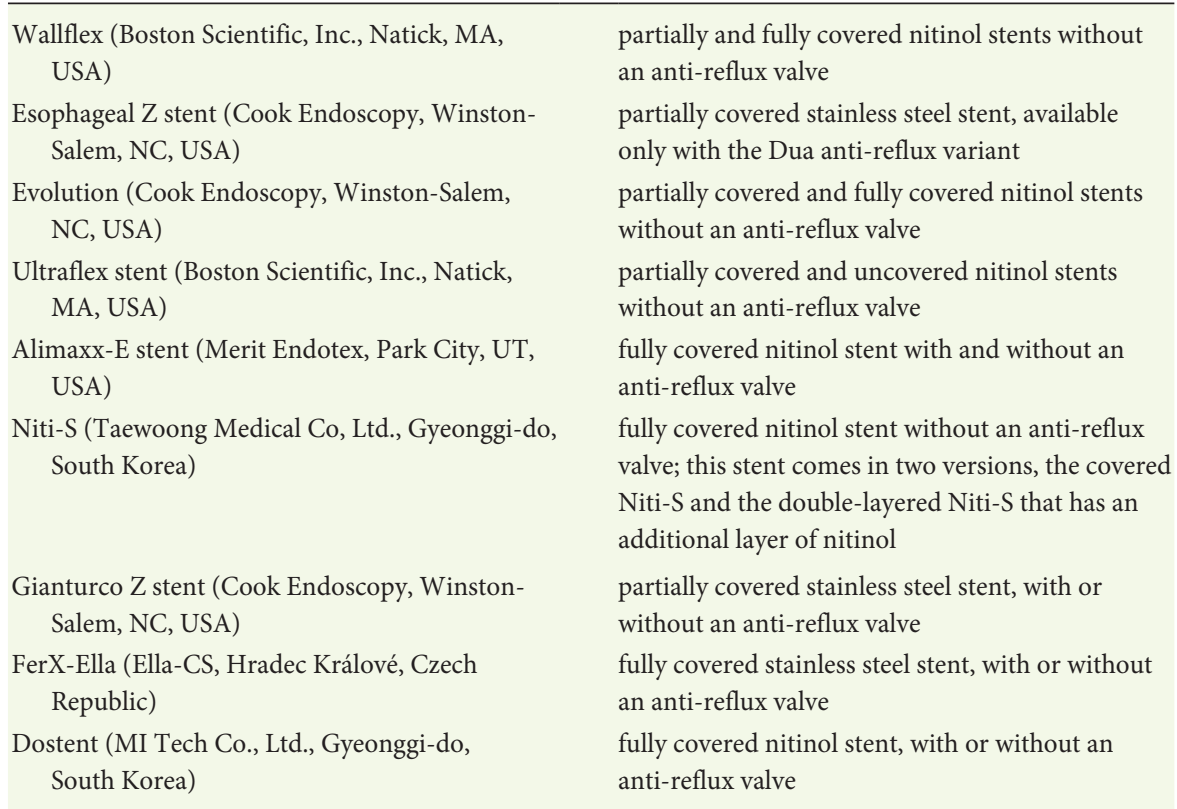

Covered stents have the advantage that tumor ingrowth can be avoided; however, they show the highest risk of dislocation. To overcome this problem, partially covered stents have an uncovered part of about $20 \mathrm{~mm}$ length at the distal and proximal end of the stent, which additionally has a greater diameter than the middle part. This allows for embedding in the tissue and for avoiding migration. An additional advantage of covered stents is the therapeutic use in case of fistulas between the esophagus and the airways or mediastinum.

Usually, SEMS are placed endoscopically with or without fluoroscopic control. Different radio-visible markers inside or outside of the body are used to mark the distal and proximal end of the tumor stenosis. The stent should protrude from the tumor margins by at least $2 \mathrm{~cm}$. Most of the current stent systems allow correction of the position during placement until a 'point of no return' is reached - usually about $50 \%$ of the total stent length. With some experience, even later corrections of the position can be successful. In case of esophagogastric placement it is necessary to avoid distal stent impaction in the opposite gastric wall with the consequences of ulceration, bleeding, and obstruction. Usually, the distal end should reach several centimeters into the stomach. Concomitant anti-reflux medication is mandatory in case of esophagogastric stent placement to avoid reflux-induced complications. Stent placement in the proximal esophagus and the region of the upper esophageal sphincter can be technically difficult.

A special problem is the presence of large extraesophageal tumor masses involving the airway tract as well. Mechanical bronchial obstruction may happen during the expansion of the stent. Therefore, prior bronchoscopy is recommendable and tentative dilation of the esophagus nearly up to the final stent diameter may be helpful to test the consequences before stent insertion. In case of doubt prior airway stenting should be performed before esophageal stenting is carried out.
An improvement after stent therapy is defined as toleration of at least oral liquids for nutrition; however, most patients are able to eat regular food as long as they avoid long fiber vegetables and meat. Under these conditions, clinical success can be expected in about $95 \%$ of patients suffering from dysphagia [35-40]. A successful closure of fistula is possible in $70-100 \%$ [41-43]. Another study showed patency times of 94,78 , and $67 \%$ at 30,90 , and 180 days, respectively [44]. Long-term survivors after SEMS implantation therefore require additional interventions over time to treat recurrence of dysphagia. One large comparative study analyzed SEMS versus rigid plastic tubes, SEMS versus laser, and SEMS versus brachytherapy [45]. SEMS were superior to rigid plastic tubes and equivalent to laser therapy (in case of given availability of laser), while the superiority of SEMS over brachytherapy in the shortterm relief of dysphagia and the superiority of brachytherapy over SEMS for long-term survivors could be shown.

The incidence of serious adverse events after stent placement is low, although $0.5-2.0 \%$ of patients die as a direct consequence of sedation, endoscopy, or stent placement. The major complications are aspiration, stent malposition, ulceration, and esophageal perforation. Chest pain, foreign body sensation, bleeding, tracheal compression, respiratory arrest, fistula formation, gastroesophageal reflux, stent migration, and stent occlusion may occur in the following. Overall, complications are more likely in case of prior radiation or radiochemotherapy; however, especially tracheoesophageal fistula formation in patients undergoing stent placement for EC is a typical complication which is significantly associated with radiation therapy. In retrospective studies, the risk of fistula formation is calculated to be about $5 \%$. However, in a current prospective study, tracheoesophageal fistula developed in $9 \%$, and all patients (with the exception of one) received radiation therapy after stent placement (17/18), while prior radiation did not increase the risk of fistula [46]. An overview of adverse events after SEMS placement is provided by a large survey study of 434 SEMS [47]. 


\section{Self-Expandable Plastic Stents}

Self-expandable plastic stents have the potential advantage of inducing fewer traumas to surrounding tissue and less tissue hyperplasia; furthermore, they are removable. In clinical studies, unfortunately, they resulted in more adverse events compared to SEMS, especially stent migration [48, 49]. Other studies showed the efficacy of plastic stents as a bridging procedure before operative therapy to overcome dysphagia during the waiting period and to achieve weight gain [50-53]. No operative difficulties arose neither when the stent was removed prior to operation nor when the stent was resected together with the tumor.

\section{Self-Expandable Biodegradable Stents}

Self-expandable biodegradable stents are made of woven surgical suture material. These uncovered stents degrade within approximately 3 months and are able to reduce dysphagia during neoadjuvant therapy $[54,55]$.

\section{Percutaneous Endoscopic (or Sonographic) Gastrostomy}

Prophylactic application of a percutaneous endoscopic gastrostomy (PEG) is recommended in many centers prior to neoadjuvant or palliative radiochemotherapy of EC. Inflammation of the mucosa, swelling of the tumor, and complications like fungal infections may worsen dysphagia during treatment, and this may compromise the success. Thus, a prophylactic PEG may be helpful [56]. In the case of cure it is removed accordingly; however, in many cases of incomplete response to therapy with residual cancer or in case of recurrence a PEG guarantees feeding, fluid intake, and medication in the final stage of the disease. Nevertheless, endo- scopic PEG placement is also possible in the final stage if dilation therapy prior to PEG placement can be performed successfully. In other cases sonographically guided direct puncture of the stomach is the alternative. All EC patients in advanced tumor stages are immunologically compromised, and all tumors show an overgrowth with bacteria and fungi. Thus, prophylactic administration of antibiotics is strictly recommended prior to and 1-3 days after PEG placement in order to avoid infectious complications.

\section{Bleeding}

Bleeding may happen at any time in patients who suffer from EC: initially as an onset of the disease, during diagnostic evaluation, during any kind of treatment, and in the final stage after all possibilities of treatment are exhausted. The endoscopic methods to stop bleeding are the same as for any other cause of bleeding, i.e. injection therapy, clipping, and coagulation therapy by means of different technical devices. A new clotting powder is also available; this can be useful if the bleeding site cannot be exactly located. Usually, coagulation therapy with APC is used as a first choice since it is commonly available; it enables the coagulation of superficially large areas of the bleeding tumor as well as the additional ablation of some of the intraluminal tumor mass. Endoscopic therapy may be difficult in high-grade stenosis of the esophagus.

\section{Disclosure Statement}

There is no conflict of interest.

\section{References}

1 Bethge N, Sommer A, Vakil N: A prospective trial of self-expanding metal stents in the palliation of malignant esophageal strictures near the upper esophageal sphincter. Gastrointest Endosc 1997;45:300-303.

$\checkmark 2$ Fokas E, Rödel C: Definitive, preoperative, and palliative radiation therapy of esophageal cancer. Viszeralmedizin 2015;31:347-353.

3 Bethge N, Sommer A, Vakil N: Palliation of malignant esophageal obstruction due to intrinsic and extrinsic lesions with expandable metal stents. Am J Gastroenterol 1998;93:1829-1832.

4 Jacobson BC, Hirota W, Baron TH, et al: The role of endoscopy in the assessment and treatment of esophageal cancer. Gastrointest Endosc 2003;57:817-822.

5 Sreedharan A, Harris K, Crellin A, et al: Interventions for dysphagia in oesophageal cancer. Cochrane Database Syst Rev 2009;4:CD005048.

6 ASGE Standards of Practice Committee, Evans JA, Early DS, et al: The role of endoscopy in the assessment and treatment of esophageal cancer. Gastrointest Endosc 2013;77:328-334.

7 Boyce HW Jr: Palliation of dysphagia of esophageal cancer by endoscopic lumen restoration techniques. Cancer Control 1999;6:73-83.
Lundell L, Leth R, Lind T, et al: Palliative endoscopic dilatation in carcinoma of the esophagus and esophagogastric junction. Acta Chir Scand 1989;155:179-184

9 Haddad NG, Fleischer DE: Endoscopic laser therapy for esophageal cancer. Gastrointest Endosc Clin N Am 1994;4:863-874.

10 Mellow MH, Pinkas H: Endoscopic laser therapy for malignancies affecting the esophagus and gastroesophageal junction. Analysis of technical and functional efficacy. Arch Intern Med 1985;145:1443-1446.

11 Eickhoff A, Jakobs R, Schilling D, et al: Prospective nonrandomized comparison of two modes of argon beamer (APC) tumor desobstruction: effectiveness of the new pulsed APC versus forced APC. Endoscopy 2007;39:637-642.

12 Rupinski M, Zagorowicz E, Regula J, et al: Randomized comparison of three palliative regimens including brachytherapy, photodynamic therapy, and APC in patients with malignant dysphagia (CONSORT 1a) (Revised II). Am J Gastroenterol 2011;106:1612-1620.

13 Marcon NE: Photodynamic therapy and cancer of the esophagus. Semin Oncol 1994;21(suppl):20-23.

14 Lightdale CJ, Heier SK, Marcon NE, et al: Photodynamic therapy with porfimer sodium versus thermal ablation therapy with Nd:YAG laser for palliation of esophageal cancer: a multicenter randomized trial. Gastrointest Endosc 1995;42:507-512.
15 Fleischman EH, Kagan AR, Bellotti JE, et al: Effective palliation for inoperable esophageal cancer using intensive intracavitary radiation. J Surg Oncol 1990;44: 234-237.

16 Jager JJ, Pannebakker M, Rijken J, et al: Palliation in esophageal cancer with a single session of intraluminal irradiation. Radiother Oncol 1992;25:134-136.

17 Sur RK, Levin CV, Donde B, et al: Prospective randomized trial of HDR brachytherapy as a sole modality in palliation of advanced esophageal carcinoma - an International Atomic Energy Agency study. Int J Radiat Oncol Biol Phys 2002;53:127-133.

18 Homs MY, Steyerberg EW, Eijkenboom WM, et al: Single-dose brachytherapy versus metal stent placement for the palliation of dysphagia from oesophageal cancer: multicentre randomised trial. Lancet 2004;364: 1497-1504.

19 Bergquist H, Wenger U, Johnsson E, et al: Stent insertion or endoluminal brachytherapy as palliation of patients with advanced cancer of the esophagus and gastroesophageal junction. Results of a randomized, controlled clinical trial. Dis Esophagus 2005;18:131-139.

20 Chung SC, Leong HT, Choi CY, et al: Palliation of malignant oesophageal obstruction by endoscopic alcohol injection. Endoscopy 1994;26:275-257. 
21 Moreira LS, Coelho RC, Sadala RU, Dani R: The use of ethanol injection under endoscopic control to palliate dysphagia caused by esophagogastric cancer. Endoscopy 1994;26:311-314.

22 Ramakrishnaiah VP, Ramkumar J, Pai D: Intratumoural injection of absolute alcohol in carcinoma of gastroesophageal junction for palliation of dysphagia. Ecancermedicalscience 2014;8:395.

23 Monga SP, Wadleigh R, Sharma A, et al: Intratumoral therapy of cisplatin/epinephrine injectable gel for palliation in patients with obstructive esophageal cancer. Am J Clin Oncol 2000;23:386-392.

24 Harbord M, Dawes RF, Barr H, et al: Palliation of patients with dysphagia due to advanced esophageal cancer by endoscopic injection of cisplatin/epinephrine injectable gel. Gastrointest Endosc 2002;56:644-651.

25 Cash BD, Johnston LR, Johnston MH: Cryospray ablation (CSA) in the palliative treatment of squamous cell carcinoma of the esophagus. World J Surg Oncol 2007. $5: 34$.

26 Greenwald BD, Dumot JA, Abrams JA, et al: Endoscopic spray cryotherapy for esophageal cancer: safety and efficacy. Gastrointest Endosc 2010;71:686-693.

27 Inoue $\mathrm{H}$, Takeshita K, Hori $\mathrm{H}$, et al: Endoscopic mucosal resection with a cap-fitted panendoscope for esophagus, stomach, and colon mucosal lesions. Gastrointest Endosc 1993;39:58-62.

28 Ell C, May A, Gossner L, et al: Endoscopic mucosal resection of early cancer and high-grade dysplasia in Barrett's esophagus. Gastroenterology 2000;118:670-677.

29 May A, Gossner L, Behrens A, et al: A prospective randomized trial of two different endoscopic resection techniques for early stage cancer of the esophagus. Gastrointest Endosc 2003;58:167-175.

30 Shimizu Y, Kato M, Yamamoto J, et al: EMR combined with chemoradiotherapy: a novel treatment for superficial esophageal squamous-cell carcinoma. Gastrointest Endosc 2004;59:199-204.

- 31 Pech O, May A, Manner H, Behrens A, Pohl J, Weferling M, Hartmann U, Manner N, Huijsmans J, Gossner L, Rabenstein T, Vieth M, Stolte M, Ell C: Long-term efficacy and safety of endoscopic resection for patients with mucosal adenocarcinoma of the esophagus. Gastroenterology 2014;146:652-660.

- 32 Manner H, Pech O, Heldmann Y, May A, Pohl J, Behrens A, Gossner L, Stolte M, Vieth M, Ell C: Efficacy, safety, and long-term results of endoscopic treatment for early stage adenocarcinoma of the esophagus with low-risk sm1 invasion. Clin Gastroenterol Hepatol 2013;11:630-635.
3 Bolton JS, Fuhrman GM, Richardson WS: Esophageal resection for cancer. Surg Clin North Am 1998;78: 773-794.

34 Mannell A, Becker PJ, Nissenbaum M: Bypass surgery for unresectable oesophageal cancer: early and late results in 124 cases. Br J Surg 1988;75:283-286.

35 Acunaş B, Rozanes I, Akpinar S, et al: Palliation of malignant esophageal strictures with self-expanding nitinol stents: drawbacks and complications. Radiology 1996;199:648-652.

36 Saxon RR, Morrison KE, Lakin PC, et al: Malignant esophageal obstruction and esophagorespiratory fistula: palliation with a polyethylene-covered Z-stent. Radiology 1997;202:349-354.

37 Ell C, May A, Hahn EG: Gianturco-Z stents in the palliative treatment of malignant esophageal obstruction and esophagotracheal fistulas. Endoscopy 1995; 27:495-500.

38 Winkelbauer FW, Schöfl R, Niederle B, et al: Palliative treatment of obstructing esophageal cancer with nitinol stents: value, safety, and long-term results. AJR Am J Roentgenol 1996;166:79-84.

39 Rozanes I, Poyanli A, Acunaş B: Palliative treatment of inoperable malignant esophageal strictures with metal stents: one center's experience with four different stents. Eur J Radiol 2002;43:196-203.

40 Siersema PD, Hop WC, van Blankenstein M, et al: A comparison of 3 types of covered metal stents for the palliation of patients with dysphagia caused by esophagogastric carcinoma: a prospective, randomized study. Gastrointest Endosc 2001;54:145-153.

41 Raijman I, Siddique I, Ajani J, Lynch P: Palliation of malignant dysphagia and fistulae with coated expandable metal stents: experience with 101 patients. Gastrointest Endosc 1998;48:172-179.

42 Morgan RA, Ellul JP, Denton ER, et al: Malignant esophageal fistulas and perforations: management with plastic-covered metallic endoprostheses. Radiology 1997;204:527-533.

43 Verschuur EM, Kuipers EJ, Siersema PD: Esophageal stents for malignant strictures close to the upper esophageal sphincter. Gastrointest Endosc 2007;66:10821090.

44 Im JP, Kang JM, Kim SG, et al: Clinical outcomes and patency of self-expanding metal stents in patients with malignant upper gastrointestinal obstruction. Dig Dis Sci 2008;53:938-945.

45 Dai Y, Li C, Xie Y, et al: Interventions for dysphagia in oesophageal cancer. Cochrane Database Syst Rev 2014; 10:CD005048.
46 Park JY, Shin JH, Song HY, et al: Airway complications after covered stent placement for malignant esophageal stricture: special reference to radiation therapy. AJR Am J Roentgenol 2012;198:453-459.

47 Ramirez FC, Dennert B, Zierer ST, Sanowski RA: Esophageal self-expandable metallic stents - indications, practice, techniques, and complications: results of a national survey. Gastrointest Endosc 1997;45: 360-364.

48 Conio M, Repici A, Battaglia G, et al: A randomized prospective comparison of self-expandable plastic stents and partially covered self-expandable metal stents in the palliation of malignant esophageal dysphagia. Am J Gastroenterol 2007;102:2667-2677.

49 Verschuur EM, Repici A, Kuipers EJ, et al: New design esophageal stents for the palliation of dysphagia from esophageal or gastric cardia cancer: a randomized trial. Am J Gastroenterol 2008;103:304-312.

50 Adler DG, Fang J, Wong R, et al: Placement of Polyflex stents in patients with locally advanced esophageal cancer is safe and improves dysphagia during neoadjuvant therapy. Gastrointest Endosc 2009;70:614-619.

51 Siddiqui AA, Glynn C, Loren D, Kowalski T: Selfexpanding plastic esophageal stents versus jejunostomy tubes for the maintenance of nutrition during neoadjuvant chemoradiation therapy in patients with esophageal cancer: a retrospective study. Dis Esophagus 2009;22:216-222.

52 Bower M, Jones W, Vessels B, et al: Nutritional support with endoluminal stenting during neoadjuvant therapy for esophageal malignancy. Ann Surg Oncol 2009;16:3161-3168.

53 Brown RE, Abbas AE, Ellis S, et al: A prospective phase II evaluation of esophageal stenting for neoadjuvant therapy for esophageal cancer: optimal performance and surgical safety. J Am Coll Surg 2011;212:582-588.

54 Hirdes MM, Siersema PD, van Boeckel PG, Vleggaar FP: Single and sequential biodegradable stent placement for refractory benign esophageal strictures: a prospective follow-up study. Endoscopy 2012;44:649-654.

55 Hirdes MM, van Hooft JE, Wijrdeman HK, et al: Combination of biodegradable stent placement and singledose brachytherapy is associated with an unacceptably high complication rate in the treatment of dysphagia from esophageal cancer. Gastrointest Endosc 2012;76: 267-274.

56 Ogino A, Akiho H: Usefulness of percutaneous endoscopic gastrostomy for supportive therapy of advanced aerodigestive cancer. World J Gastrointest Pathophysiol 2013;4:119-125. 